\title{
A STUDY ON CONSTRUCTION OF AN INVESTMENT PORTFOLIO USING FUNDAMENTAL ANALYSIS
}

\author{
Dr. M. Rajeswari \\ Professor, School of Management, \\ Hindustan Institute of Technology and Science, (HITS), India
}

\begin{abstract}
The recession period has made the retail investor to think about his investment plans. To aid the retail investor this study has been undertaken by the researcher. To invest in a fortune company the fundamental analysis is a good start.

The retail investor cannot afford the ill decision made without any analysis about the company. The fundamental analysis is totally based on the financial performance of the company. The financial performance analysis could help the initial investors get impressed by the company and may influence them to make investments in the company.

The researcher has taken three sectors for the study, which tops even in the recession period. The researcher has collected secondary data-Balance sheet and Income statement - of the companies for the period of last 3 years (2016-2017 to 2018-2019)
\end{abstract}

Key words: Investment Decision, Behaiour Index, stocking point.

Cite this Article: M. Rajeswari, A Study on Construction of an Investment Portfolio using Fundamental Analysis, International Journal of Management, 11(12), 2020, pp 415-429.

http://iaeme.com/Home/issue/IJM?Volume=11\&Issue=12

\section{INTRODUCTION}

\subsection{Background of the Study}

Fundamental analysis is the cornerstone of investing. In fact, some would say that you aren't really investing if you aren't performing fundamental analysis. Because the subject is so broad, however, it's tough to know where to start. There are an endless number of investment strategies that are very different from each other, yet almost all use the fundamentals.

The goal of this study is to provide a foundation for understanding fundamental analysis. It's geared primarily at new investors who don't know a balance sheet from an income statement. While the investor may not be a "stock-picker extraordinaire" by the end of this 
study, the investor will have a much more solid grasp of the language and concepts behind security analysis and be able to use this to further your knowledge in other areas without feeling totally lost.

The biggest part of fundamental analysis involves delving into the financial expenses, assets, liabilities and all the other financial aspects of a company. Fundamental analysts look at this information to gain insight on a company's future performance. A good part of this study will be spent learning about the balance sheet, income statement, cash flow statement and how they all fit together.

But there is more than just number crunching when it comes to analyzing a company. This is where qualitative analysis comes in - the breakdown of all the intangible, difficult-tomeasure aspects of a company.

In this study researcher has attempted to study the financial position of the choosen companies using the traditional approach to investing -fundamental approach. Various factors of the company like Sales, Profit, Taxes paid, Earnings Per Share, Dividend Payout Ratio, PE (PROSPECTIVE), etc. Were analyzed in the fundamental approach and necessary suggestions were made for the clients of Indian Overseas Bank.

\subsection{Need \& Scope of the Study}

Fundamental analysis is based on the premise that a security has an intrinsic value at any given point of time. This value is a function of two underlying economic values - expected returns and risk. By assessing these fundamental determinants of the intrinsic value of a security, it is thus possible to estimate an intrinsic value for the stock. This estimated intrinsic value can then be compared to the current market price of the security.

A basic assumption of fundamental analysis is that market price and intrinsic value can differ from time to time. But eventually investors will recognize the discrepancy and act to bring the two values together. Those investors are good at fundamental analysis and can spot discrepancies are able to make profits by taking a suitable decision before the market corrects the disparity.

The proper order in which to proceed with fundamental analysis is, first, to analyze the overall economy and securities markets. Second, analyze the industry within which a particular company operates. Finally, analysis of the company should be considered. The above analysis involves making careful estimates of the expected stream of benefits and the required rate of return (this will depend on the risk) for a common stock. The intrinsic value can then be obtained through the present value analysis - that is, the dividend discount model. An alternative method of valuation I, is the P/E ratio or an earnings multiplier approach.

The researcher has taken three sectors for the study which tops even in the recession period. The researcher has collected secondary data - Balance sheet and Income statement of the companies for the period of last 3 years (2016-2017 to 2018-2019)

\subsection{Objectives of Study}

- To evaluate the chosen sectors and companies within those sectors on the basis of the many financial parameters such as Operation Profit, Profit before tax , Net profit, Sales, Operating profit margin, Interest, Other incomes, Depreciation, tax etc.

- To calculate the average value of the chosen sectors and company's within those sectors in order to construct a profitable portfolio invest. 


\section{LITERATURE SURVEY}

\subsection{Review of Literature}

The literature review is a study involving a collection of literatures in the selected area of research in which the researcher has limited experience, and critical examination and comparison of them to have a better understanding. It also helps the researchers to update the past data, data sources and results and identify the gaps, if any in the researches. Thus, the reviews in the present study consist of the ones discussed below and they reveal that there are very scant studies in India emphasizing on the fundamental analysis

As per the project articles were reviewed and summaries of the same are listed below:

J Hema and V Ariram (2016) in their research paper titled, " Fundamental analysis with special reference to pharmaceutical companies listed in NSE" stated that an investor should analyze the market fundamentally and technically before investing in shares. They also noticed growth in the pharmaceutical industry in India.

Hemraj Verma and Prakash Tiwari (2010) in their study, headed "A Fundamental analysis of public sector banks in India" detailed the growth of the Indian banking industry and current performance of the bank with the help of various ratios.

Sugandharaj Kulkarni (2011) in his research paper titled, “ A study on fundamental analysis of ONGC" explains about the relevance of fundamental analysis along with the attempt to find the intrinsic value of shares.

Venkatesh C K and Madhu Tyagi (2011) in their research paper titled, "Fundamental analysis as a method of share valuation in comparison with technical analysis" detailed about different movement of share prices in comparison with fundamental and technical analysis. It also emphasized on the market capitalization and organizational structure.

Ahmed S Wafi, Hassan and Abel Mabrouk (2015) in their learning headed, " Fundamental analysis models in financial market" presented in third economic and finance conference in Rome. This paper aims to find the better stock valuation model using the fundamental analysis approach.

Jim Berg (2012) conducted a study - "Fundamental Analysis Using Internet". This study examined that fundamental analysis looks at the fundamental issues that drive the value of the particular company. These issues include its financial position, its industry sector, and the current economic environment. The objective was to identify companies that may be considered undervalued in the market with a view to investing when the time is right. In this study, Jim Berg outlined more about what fundamental analysis is and how it could be used.

In this study, John Colnan (1994), senior Research Analyst form SHAN Stockbroking's Research Department provides some brief pointers on what information to look for and how to make sense of what is available.

Mark P. Bauman (2013) conducted a study named, "A Review of Fundamental Analysis Research in Accounting". This paper has outlined the development of fundamental valuation model and reviewed related empirical work. First, an accounting-based expression for a firm's equity value has been developed into a rich theoretical framework. He verified its descriptive validity regarding the mapping of accounting numbers into stock prices. This paper identified three major issues associated with practical implementation of the model; the prediction of future profitability, the length of appropriate forecast horizon, and the determination of the appropriate discount rate.

Jon Lynch conducted a study, "Share Market Analysis : Fundamental Vs Technical Analysis", which reveals that in recent times, there has been a bigger push towards stock market research, which is being conducted by private individuals. This has been possible 
through the vast amount of information on the Australian stock market, now available online to any subscriber. This article explains the difference between the fundamental and technical analysis; the most common methods adopted to conduct research on the performance of stock markets.

Vanstone B. Finnie G. and Tan C. (2004) conducted a study entitled- "Enhancing Security Selection in the Australian Stock Market Using Fundamental Analysis and Neural Networks". This paper examines financial trading from the aspect of security selection. In practice, it is unrealistic for a financial trader to participate in the fill market of tradable securities competing for investment capital. Essentially, there are two main methodologies used, namely, fundamental analysis and technical analysis. This paper examines the practice of fundamental analysis and demonstrates how neural networks can be practically employed to enhance the fundamentalist selection process.

Dr. Maria Nevis Soris and V. Sornaganesh (2012) conducted a study entitled"Fundamental Analysis of NBFC in India" This study conducted to examine the economic sustainability of the five major NBFC in Indian NBFC sector and its financial performance. 3 Need and objectives of the study An investor who would like to be rational and scientific in his investment activity has to evaluate a lot of information about the past performance of the companies, industries and the economy as a whole before taking the investment decision and hence, the present study attempts to analyze the profitability position of the sample companies.

\section{RESEARCH METHODOLOGY}

\subsection{Type of Research}

A research design is the arrangement of conditions for collection and analysis of data in a manner that aims to combine relevance to the research purpose with economy in procedure. The research design is the Descriptive structure within which research is conducted. It constitutes the blueprint for the collection, measurement and analysis of data.

\section{Target Respondents}

Secondary data: The project work will be completely based on Secondary data. Data would be collected through from the stock market websites such as NSE, etc. Financial Statements of the companies are employed for the analysis

\section{Assumptions, Constraints and Limitations}

- All the data would be collected from the secondary sources such as Magazines, Websites, Annual reports, manuals etc.

- The non-availability of information about the additional capital employed for each year, could make the research to stick on to absolute value and not with the percentage of increase or decrease in the values.

- Only 3 years of clear past financial data of the companies would be taken for analysis..

- The accuracy of the derived values would depend upon the reliability of the data in the secondary sources.

\section{Fundamental Analysis}

\section{Bombay Stock Exchange (BSE)}

BSE is called Bombay stock exchange Bombay stock exchange is the oldest stock exchange in Asia with a rich heritage, now spanning three centuries in its 133 years of existence. What is now popularly known as BSE was established as 'the native share \&stock brokers 
association' in 1875 BSE is the first stock exchange in the country which obtained permanent recognition in 1956 from posted in Mumbai.

\section{National Stock Exchange (NSE)}

The national stock exchange of India limited was set up on basis of the recommendation of the high powered study group on establishment on new stock exchanges. The NSE is not an exchange in the traditional sense of the term, where brokers own and manage the exchange. Its two tier administrative set up involves a company board and a governing board of exchange.

\section{Seven risks involved for the investor}

Default risk: This is the most frightening of all investment risks. The risk of non- payment refers to both the principle and the interest. For all unsecured loans eg.loans based on promissory notes etc. This risk is very high.

Business risk: The market value of your investment in equity shares depends upon the performance of the company in which we invest. if a company's business suffers and the company does not perform well, the market value of the share can go down sharply. This invariably happens in the case of shares of companies which hit the IPOs market with issues at high premiums when the economy is in a good condition and the stock markets are bullish.

Liquidity risk: Money has only a limited value if it is not readily available to you as and when needed. In financial jargon the ready availability of money is called liquidity. An investment should not only be safe and profitable but also reasonably liquid. Current and savings account in a bank, national savings certificates, and actively traded equity shares and debentures etc.are fairly liquid investments.

Inflation risk: Inflation means being broke with a lot of money in your pocket. When prices shoot up the purchasing power of researcher money goes down. Some economists consider inflation to be a disguised tax. Given the present rates of inflation, it may sound surprising but among developing countries, India is often given good marks for effective management of inflation.

Interest rate risk: In this deregulated era, interest rate fluctuation is a common phenomenon with its consequent impact on investment values and yields. Interest rate risk affects fixed income securities and refers to the risk of a change in the value of the researcher investment as a result of movement in interest rate.

Political risk: The government has extra ordinary powers to affect the economy. It may introduce legislation affecting some industries or companies in which researcher invested or it may introduce legislation granting debt-relief to certain sections of society, fixing ceilings of property etc.

Market risk: Market risk is the risk of movement in security prices due to factors that affect the market as a whole. Natural disaster can be one such factor. The most important of these factors is the phase the markets are going through stock markets and bond markets are affected by rising and falling prices due to alternating bullish and bearish periods.

\section{Approaches to avoid Risk}

\section{Fundamental Approach}

To determine the intrinsic value of an equity share, the security analysist must forecast the earnings and dividend expected from these stocks and chooses a discount rate which reflects the riskiness of the stock. 


\section{Technical Approach}

Technical analyst does not evaluate a large number of fundamental factors relating to the company, industry and the economy.

\section{Sectors taken for Analysis}

- Banking sector

- Pharmaceutical sector

- Automobile sector

\section{Tools for Analysis}

- Sales of the company

- Net profit of the company

- Operating profit

- Tax

- Operating Margin

\section{Compound Annual Growth Rate (CAGR)}

The Compounded Annual Growth Rate (CAGR) measures a market's annual growth over a period of time (usually several years). This measure is a constant percentage rate at which a market would grow or contract year on year to reach its current value . CAGR is a formula used to express the rate of growth in sales, earnings, units or some other measure over a number of years. A firm's CAGR, for example, is one of the main numbers tracked by security analysts. CAGR -based forecasts are based on projected market volume and price per unit measures. where: $\mathrm{Y}$ is the value in the final year : $\mathrm{X}$ is the value in the first year where: $\mathrm{N}$ is the number of years included in the calculation

\section{CAGR in Sales}

\section{(Sales at the Last year|Sales at the Beginning year) $1 / 2$}

\section{CAGR in EPS}

\section{(EPS at the Last year|EPS at the Beginning year) $1 / 2-1$}

\section{Price to Earning (Prospective)}

Price per share at the Beginning of the year / EPS for the year

\section{Sustainable Growth Rate (SGR)}

The maximum growth rate that a firm can sustain without having to increase financial leverage. The sustainable growth rate is a measure of how much a firm can grow without borrowing more money. After the firm has passed this rate, it must borrow funds from another source to facilitate growth.

Average of Retention Ratio (RR) x Average of Return on Equity (ROE)

\section{Return on Capital Employed (ROCE)}

ROCE is a measure of the returns that a company is realizing from its capital. The resulting ratio represents the efficiency with which capital is being utilized to generate revenue. Return on Capital Employed (ROCE) Ratio is one of the important tools used to identify companies 
that offer good value and have the potential to grow or Growth at a Reasonable Price (GARP). The return on capital employed ratio helps to identify good businesses that earn more relative to the price being paid than others.

ROCE is sometimes referred to as the "primary ratio"; it tells us what returns management has made on the resources made available to them before making any distribution of those returns.

\section{Dividend Payout Ratio}

The dividend payout ratio shows what percentage of a company's earnings it is paying out to investors in the form of dividends. It is calculated by taking the company's annual dividends per share and dividing by its annual earnings per share (EPS). So, if a company pays out Re.1 per share annually in dividends and it has an EPS of Rs.2 for the year, then that company has a dividend payout ratio of $50 \%$; in other words, the company paid out $50 \%$ of its earnings in dividends.

Companies that distribute dividends typically use about $25 \%$ to $50 \%$ of their earnings for dividend payments. The higher the payout ratio, the less confidence the company has that it would've been able to find better uses for the money it earned. This is not necessarily either good or bad; companies that are still growing will tend to have lower dividend payout ratios than very large companies, because they are more likely to have other productive uses for the earnings.

\section{Justification for the Sectors and Scrips Chosen}

The researcher has chosen the sectors and the scrips within the sectors by fully analysing the NIFTY as on $31^{\text {st }}$ of Mrach, 2019. The sectors and scrips included in the study have been given due weightage in the NIFTY.

\section{DATA ANALYSIS AND INTERPRETATIONS}

\section{Analysis and Interpretation and Discussion, Inferences}

\section{Banking Sector}

Sales Factor

Table 1 Sales factor

\begin{tabular}{|l|c|c|c|c|c|c|c|c|c|c|c|}
\hline Company & $\mathbf{2 0 1 8 - 2 0 1 9}$ & \% & $\begin{array}{c}\text { Weightage } \\
\text { on a score } \\
\text { of 5 }\end{array}$ & $\mathbf{2 0 1 7 - 2 0 1 8}$ & \% & $\begin{array}{c}\text { Weightage } \\
\text { on a score } \\
\text { of 5 }\end{array}$ & $\mathbf{2 0 1 6 - 2 0 1 7}$ & \% & $\begin{array}{c}\text { Weightage } \\
\text { on a score } \\
\text { of 5 }\end{array}$ & Aggregate & Points \\
\hline PNB & 135237.70 & 19.91 & 1.00 & 121684.07 & 17.29 & 0.86 & 107452.27 & 17.36 & 0.87 & 0.91 & 3 \\
\hline IOB & 146291.00 & 21.53 & 1.08 & 139269.46 & 19.78 & 0.99 & 118353.71 & 19.12 & 0.96 & 1.01 & 4 \\
\hline CANARA & 207382.00 & 30.53 & 1.53 & 270402.30 & 38.41 & 1.92 & 238348.37 & 38.51 & 1.93 & 1.79 & 5 \\
\hline SBI & 65716.54 & 9.67 & 0.48 & 60466.48 & 8.59 & 0.43 & 57190.17 & 9.24 & 0.46 & 0.46 & 1 \\
\hline $\begin{array}{l}\text { INDIAN } \\
\text { BANK }\end{array}$ & 124752.40 & 18.36 & 0.92 & 112098.27 & 15.92 & 0.80 & 97647.32 & 15.78 & 0.79 & 0.84 & 2 \\
\hline TOTAL & 679379.60 & 100 & & 703920.60 & 100 & & 618991.80 & 100 & & & \\
\hline
\end{tabular}

\section{Inference:}

The table shows that the aggregate point of CANARA is 1.79 and the highest among the others due to sales made by them is comparatively high. SBI banks the lowest point in the study of sales due to lower sales. INDIAN BANK and IOB made a big leap in sales in the year 2017-2018. 
Net Profit Factor

Table 2 Net profit

\begin{tabular}{|l|c|c|c|c|c|c|c|c|c|c|c|}
\hline Company & $\mathbf{2 0 1 8 - 2 0 1 9}$ & \% & $\begin{array}{c}\text { Weightage } \\
\text { on a score } \\
\text { of 5 }\end{array}$ & $\mathbf{2 0 1 7 - 2 0 1 8}$ & \% & $\begin{array}{c}\text { Weightage } \\
\text { on a score } \\
\text { of 5 }\end{array}$ & $\mathbf{2 0 1 6 - 2 0 1 7}$ & \% & $\begin{array}{c}\text { Weightage } \\
\text { on a score } \\
\text { of 5 }\end{array}$ & Aggregate & Points \\
\hline PNB & 735.90 & 3.34 & 0.17 & 1580.56 & 3.45 & 0.17 & 1805.48 & 4.69 & 0.23 & 0.19 & 2 \\
\hline IOB & 15279.00 & 6.93 & 0.35 & 19458.29 & 42.45 & 2.12 & 11943.40 & 31.05 & 1.55 & 1.34 & 4 \\
\hline CANARA & 2949.55 & 13.38 & 0.67 & 6962.58 & 15.19 & 0.76 & 7499.47 & 19.50 & 0.97 & 0.80 & 3 \\
\hline SBI & 16261.31 & 73.75 & 3.69 & 16701.65 & 36.44 & 1.82 & 15642.92 & 40.67 & 2.03 & 2.51 & 5 \\
\hline $\begin{array}{l}\text { INDIAN } \\
\text { BANK }\end{array}$ & 574.98 & 2.61 & 0.13 & 1134.88 & 2.48 & 0.12 & 1571.17 & 4.08 & 0.20 & 0.15 & 1 \\
\hline TOTAL & 22049.64 & 100 & & 45837.96 & 100 & & 38462.44 & 100 & & & \\
\hline
\end{tabular}

Net profit

\section{Inference}

The aggregate point of SBI is 2.51 and the highest among the others due to net profit made by them is comparatively high. INDIAN BANK banks the lowest point in the study of net profit due to less net profit.

\section{Operating Profit Margin Factor}

\section{Inference}

The aggregate point of SBI is 2.55 and the highest among the others due to operating profit margin made by them is comparatively high. INDIAN BANK banks the lowest point in the study of operating profit margin due to lower operating profit.

\section{Tax Factor}

\section{Inference:}

The aggregate point of SBI is 2.83 and the highest among the others due to tax made by them are comparatively high. INDIAN BANK banks the lowest point in the study of tax due to lower net profit. CANARA pays the medial tax.

\section{CAGR in Sales}

(Sales at the Last year|Sales at the Beginning year) $1 / 2$

\section{CAGR in Sales}

\section{Inference:}

The point of INDIAN BANK is 1.13 and the highest among the others due to CAGR in SALES made by them are comparatively high. CANARA banks the lowest point in the study of CAGR in SALES.

\section{CAGR in EPS}

(EPS at the Last year|EPS at the Beginning year) $1 / 2-1$

\section{CAGR in EPS}

\section{Inference:}

The point of IOB is 0.09 and the highest among the others due to CAGR in EPS made by them are comparatively.

INDIAN BANK gets the lowest point in the study of CAGR in EPS. 


\title{
PE (Prospective) Factor
}

Price per share at the Beginning of the year / EPS for the year PE (PROSPECTIVE)

\section{Inference:}

The aggregate point of IOB is 3.19 and the highest among the others due to PE made by them are comparatively high.INDIAN BANK banks the lowest point in the study of PE (PROSPECTIVE).

\section{Sustainable Growth Rate (SGR)}

Average of Retention Ratio (RR) x Average of Return on Equity (ROE)

\section{Sustainable Growth Rate (SGR)}

\section{Inference}

The table shows that the aggregate point of CANARA and INDIAN BANK are and the highest among the others due to ROE made by them are comparatively high. IOB banks the lowest point in the study of SGR.

\section{Return on Capital Employed}

\author{
Net Profit \\ Capital Employed $\times 100$
}

\section{Inference:}

The aggregate point of SBI is the highest among the others due to ROCE made by them are comparatively high. PNB and INDIAN BANK the lowest point in the study of ROCE.

\section{Dividend Payout Ratio}

\section{Divend Per Share}

\section{Earnings Per Share}

\section{DP Ratio}

\section{Inference:}

The aggregate point of SBI is the highest among the others due to Dividend paid is comparatively high. PNB and INDIAN BANK bank the lowest point in the study of ROCE.

\section{Inference}

Among the five companies in the banking sector, SBI scores the first rank. The last rank is obtained by PNB.

\section{Pharmaceutical Sector}

\section{Sales Factor}

\section{Inference:}

The aggregate point of Lupin Ltd is 1.32 and the uppermost among the others due to sales made by them is fairly.

Glaxo SmithKline gets the smallest point in the study of sales due to fewer sales. Sun Pharma made a big leap in sales in the year 2018-2019. 


\section{Operating Profit}

\section{Operating Profit Factor}

Inference: The table shows that the aggregate point of Cipla is 1.46 and the highest among the others due to operating profit made by them is comparatively high. Sun Pharma banks the lowest point in the study of operating profit. Dr.Reddys made a big leap in operating profit in the year 2007-2008.

\section{Operating Profit Margin Factor \\ Operating Profit Margin}

\section{Inference:}

The aggregate point of Glaxo SmithKline is 1.96 and the highest among the others due to operating profit margin made by them is relatively high.Lupin Ltd collect the lowest point in the study of operating profit margin.Sun pharma made a big leap in operating profit in the year 2007-2008.

\section{TAX FACTOR}

\section{Inference:}

The aggregate point of Glaxo SmithKline is 1.93 and the highest among the others due to tax made by them are relatively high. Lupin Ltd get the lowest point in the study of tax due to lower net profit. Cipla pays the medial tax.

\section{CAGR in Sales}

(Sales at the Last year|Sales at the Beginning year) $1 / 2$

\section{CAGR in Sales}

\section{Inference}

The point of Sun Pharma is 1.50 and the maximum among the others due to CAGR in SALES made by them are comparatively high. Lupin Ltd banks the lowest point in the study of CAGR in SALES.

\section{CAGR IN EPS :CAGR IN EPS}

(EPS at the Last year|EPS at the Beginning year) $1 / 2-1$

\section{Inference:}

The point of Sun Pharma is 0.37 and the highest among the others due to CAGR in EPS made by them are reasonably high. Lupin Ltd get the lowest point in the study of CAGR in EPS.

\section{PE (Prospective) Factor}

Price per share at the Beginning of the year / EPS for the year

\section{Inference:}

The aggregate point of Sun Pharma is 5.02 and the highest among the others due to PE (PROSPECTIVE) made by them is moderately high. Lupin Ltd bank the smallest point in the study of PE (PROSPECTIVE). Dr. Reddys made a big leap in PE (PROSPECTIVE) in the year 2008-2009. 


\title{
Sustainable Growth Rate (SGR)
}

Average of Retention Ratio

(RR)x Average of Return on Equity (ROE) Sustainable Growth Rate (SGR)

Inference:

The SGR of Cipla and Dr. Reddys is same based on the points allotted to them in each year and the highest among the others. Lupin Ltd and Glaxo SmithKline bank the lowest point in the study of Retention Ratio.

\section{Return on Capital Employed}

\author{
Net Profit \\ $\overline{\text { Capital Employed }} \times 100$
}

\section{ROCE}

\section{Inference}

The aggregate point of Glaxo SmithKline is given based on the points allotted to them in each year and the highest among the others due to ROCE made by them is comparatively. Lupin Ltd banks the lowest point in the study of ROCE. Dr. Reddys made a big leap in ROCE in the year 2016-2017.

\section{Dividend Payout Ratio}

\section{Divend Per Share}

\section{Earnings Per Share}

\section{DP Ratio}

\section{Inference:}

The aggregate point of Glaxo SmithKline is given based on the points allotted to them in each year and the highest among the others. Lupin Ltd banks the lowest point in the study of DP ratio.

\section{Inference}

Among the five companies in the pharmaceutical sector cipla scores the first rank. The last rank is obtained by Lupin Ltd.

\section{Automobile Sector}

\section{Sales Factor}

\section{Inference:}

The aggregate point of Tata motors is 1.97 and the highest among the others due to sales made by them is comparatively high. TVS gets the lowest point in the study of sales due to fewer sales. Bajaj made a big leap in sales in the year 2016-2017 


\section{Net profit}

\section{Net Profit Factor}

\section{Inference}

The aggregate point of Tata motors is 1.58 and the top among the others due to net profit made by them is comparatively high. TVS banks the least point in the study of net profit due to less net profit. Honda made a big leap in sales in the year 2018-19.

\section{Operating profit}

\section{Inference:}

The table shows that the aggregate point of Tata motors is 1.64 and the highest among the others due to operating profit completed by them is comparatively high. TVS collects the lowest point in the study of operating profit due to fewer sales. Honda ended a big leap in operating profit in the year 2018-19.

\section{Operating Profit Margin Factor}

\section{Operating Profit Margin}

Inference: The aggregate point of Bajaj is 1.34 and have the maximum points among the others due to operating profit margin made by them is relatively high. TVS gets the lowest point in the study of operating profit margin. Maruti Suzuki finished a big leap in operating profit margin in the year 2008-2009.

\section{Tax Factor}

\section{Inference}

The table shows that the aggregate point of Maruti Suzuki is 1.69 and the highest among the others due to tax made by them are moderately high. TVS gets the lowest point in the study of tax due to lower sales and net profit. Bajaj pays the medial tax.

\section{CAGR IN SALES}

CAGR IN SALES

(Sales at the Last year|Sales at the Beginning year) $1 / 2$

\section{Inference:}

The table shows that the point of Maruti Suzuki is 1.09 and the highest among the others due to CAGR in SALES made by them are comparatively high. TVS gets the least point in the study of CAGR in SALES.

\section{CAGR IN EPS}

(EPS at the Last year|EPS at the Beginning year) $1 / 2-1$

\section{CAGR IN EPS}

\section{Inference:}

The table shows that the point of TVS is 0.44 and the highest among the others due to CAGR in EPS made by them are moderately high.

Bajaj banks the lowest point in the study of CAGR in EPS. 


\title{
PE (Prospective) Factor
}

Price per share at the Beginning of the year / EPS for the year PE (PROSPECTIVE)

\section{Inference:}

The table shows that the aggregate point of Bajaj is 24.48 and the highest among the others due to PE (PROSPECTIVE) made by them is comparatively high. Tata motors banks the lowest point in the study of PE (PROSPECTIVE). Honda prepared a big leap in PE (PROSPECTIVE) in the year 2017-2018.

\section{Sustainable Growth Rate (SGR)}

Average of Retention Ratio (RR) x Average of Return on Equity (ROE) Sustainable Growth Rate (SGR)

\section{Inference:}

The table shows that the aggregate point of TVS is uppermost among the others Honda and Bajaj collects the lowest point in the study of SGR. Maruti Suzuki completed a big leap in Retention ratio in the year 2008-2009.

\section{Return on Capital Employed}

\author{
Net Profit \\ Capital Employed $\times 100$
}

\section{ROCE}

\section{Inference:}

The table shows that the aggregate point of Honda is given based on the points allotted to them in each year and the highest among the others due to ROCE made by them is moderately high. TVS and Tata Motors collect the lowest point in the study of ROCE. Maruti Suzuki and Bajaj made a big leap in ROCE in the year 2018-2019.

\section{Dividend Payout Ratio}

\section{Divend Per Share}

\section{Earnings Per Share}

\section{DP Ratio}

\section{Inference:}

The table shows that the aggregate point of Honda is given based on the points allotted to them in each year and the highest among the others. TVS and Tata Motors collect the lowest point in the study of DP Ratio.

\section{RESULTS \&CONCLUSION}

\subsection{Findings and Suggestions}

For The Initial investors the following findings suggestions would help him to make informed decision. The researcher has adapted the fundamental approach and employed tools of analysis to arrive some conclusion 
- Among the general financial factors, the IOB scores top among five companies. But based on the investor expected factors SBI attains first.

- In the Pharma sector, sun pharma and Lupin Ltd had a tight pace with each other, but in the previous year, Lupin Ltd incurred a huge loss.

- For the past two year Lupin Ltd has not declared any dividend for the investor

- In the overall analysis of the pharma sector, Cipla gets the high preference with 3.68 points out of 5 .

- In the auto mobile sector TVS is making less sales and less profit. It is preceded by Bajaj automobiles.

- The consolidated ranking table of the automobile sector shows that High priority in investing is obtained by Honda followed by Maruti.

- The researcher would suggest the investor to make his initial investment in the sectors of study may be in the top two ranked companies

Banking Sector

Pharmaceutical Sector

Automobile Sector
SBI \& IOB

- $\quad$ Cipla \& Sun Pharma

- $\quad$ Honda \& Maruti

\section{CONCLUSION}

The capital market of any country is subject to risk. No investor wants to invest his hard earned money in whim. Every investor expects high returns with low risk. For some investors, holding a scrip of well performing company is a matter of reputation. The researcher tries to help them for making an initial step into the volatile market. The researcher strongly recommends the investors to read the audited report/ note of the appointed auditors of each company. This is because more investor information could be obtained from the note and may aid the investor in making investing decisions.

\section{REFERENCES}

[1] Hema and V Ariram (2016), "Fundamental Analysis with special reference to pharmaceutical companies listed in NSE", International journal of management, 7(2), 2016 pp 123-133.

[2] Tiwari Prakash and Verma Hemraj (2009), “A Fundamental analysis of public sector banks in India”, Indian journal of finance, Vol 3, Issue 11, November 2009.

[3] Kulkarni Sugandharaj (2012) "A study on fundamental analysis of ONGC", International journal of multidisciplinary research, Vol1, Issue 8, Dec 2011 pp 383-392.

[4] C K Venkatesh and Tyagi Madhu (2011), “ Fundamental analysis as a method of share valuation in comparison with technical analysis", Bangladesh research publications journal, Vol 5, Issue 3, May-June 2011 pp 167-174.

[5] Wafi S Ahmed Hassan Hassan Mabrouk Adel (2015), “Fundamental analysis models in financial markets- Review study”, Procedia economic and finance 30, 2015 pp 939-947.

[6] Jim Berg (1999), Fundamental Analysis using internet, past edition ASX investors update email news letter, (www.asx.com.au).

[7] John colnan (1994), Fundamental Analysis, SHAW Stock Broking Ltd., by ASX investors update e-mail newsletter, (www.qsx.com.au) 
A Study on Construction of an Investment Portfolio using Fundamental Analysis

[8] John Lynch, "Share Market Analysis-Fundamental analysis Vs. Technical Analysis", (www.eninarticle.com)

[9] Dr. Maria Nevis Soris and V.Sornaganesh (2012), Fundamental Analysis of NBFC in India, OUTREACH - A Multi-Disciplinary Refereed Journal in 2012.

[10] Punithavathy Pandian (2005) "Security Analysis and Portfolio Management" Vikas Publication Pvt Ltd, New Delhi. 